\title{
EDITORIAL
}

\section{Aspects of openness in education}

Welcome to this issue of Research in Learning Technology. The dynamic fields of education and technology, which are the focus of our journal, provide us with an ever-changing environment for innovations, lessons learnt and prospective ideas for future exploration and development. As a result, we have a continuous flow of submissions for our reviewers to consider. To ensure submissions are reviewed as quickly as possible, we encourage authors to refer to the detailed guidelines on the journal's website before sending in their work.

It is extremely gratifying to see the commitment to quality shown by our reviewers. This is a pro bono task that takes concentration and time, whilst also being rewarding and stimulating to see emerging works from scholars around the world. Excellent review processes serve to make the journal Research in Learning Technology continuously well subscribed and well reputed. Specific download data are available, just click through to the article of your choice and see the article metrics at the first screen.

The collection of articles in this issue includes research, scholarly works and longitudinal studies that continue the theme of openness that was recently evident at this year's Association for Learning Technology (ALT) conference. Both large- and small-scale works reported in this issue consider openness from a range of perspectives - identity, open educational resources, repositories and open badges. Three papers provide us with frameworks for decision making, and evaluating quality indicators and teaching/learning experiences.

The opening paper by Bennett and Folley (2014) explores the transition process during doctoral studies - a transition into new identities. Using social media tools to capture and support this self-examination, the authors report on the experiences of transitioning through liminal stages to engage with threshold concepts that lead to new identity formation.

The next paper by Bennett (2014) discusses findings from a small study on core motivations of lecturers adopting Web 2.0 technologies in teaching. Contrasting her findings with Sharpe and Beetham's (2010) model of students' digital literacies, she asserts that lecturers' motivations to ultimately improve their students' learning goes beyond the point of developing digital literacy for its own sake. Bennett reminds us of Mishra and Koehler's (2006) model that integrates technology, pedagogy and content knowledge (TPACK) as fundamental components for effective practice, and observes that lecturers in her sample appeared to be in a 'dance' with these components as they made their design decisions.

The TPACK model is the basis for our third article by Di Blas, Fiore, Mainetti, Vergallo and Paolini (2014). This very detailed work presents an excellent literature review on repositories of open educational resources (ROER) before going on to describe an Italian national project that resulted in the development of a repository of educational experiences and a portal for ease of access and retrieval. The TPACK 


\section{O'Reilly}

model is used to initially analyse and tag the 274 educational experiences gathered from pre-school to high-school. Initial evaluation shows that the repository is being used to access rich data for teaching and research.

Staying with the school sector, Orlando's (2014) article reports on a 5-year longitudinal study of the scholarly practices of Australian primary and secondary school teachers in their use of digital technology. With the benefit of such a long period for data collection, the findings of this research provide important points for consideration - the time needed for some staff to adopt changes to their practices and use technologies in teaching; the time it takes for some to gain momentum in their own reflective practices; and the impact of context upon practicing teachers. Given this need for time and support that allow reflections and practices to grow and ripen, we are left to ask: How do we ensure we can suitably pace ourselves for on-going and sustainable improvement to practice?

Another longitudinal study is reported by Scott (2014), and this single case study over two years provides a fine example of how changes to practice can occur with time, reflection and collegial support. The challenge of taking over someone's e-learning design with no lead-time prior to teaching, and subsequently preparing changes for future delivery, are explored from the point of view of Jennifer's case - whose elearning beliefs and practices were directly influenced by her experiences and reflections. The salient point in this case study relates to the importance of collaboration and preparation of legacy documents on design, pedagogy and technology in teaching. Such strategies to ensure effective reuse of resources provide an excellent segue to our next article on open educational resources.

Atenas and Havemann (2014) discuss open educational resources, in terms of resource-based and creative learning design together with scholarly collaboration, as being key to culture change in academia. The typical constraints on open educational resources are cited - the lack of incentives to share, the investment in repurposing versus creating, and the uncertainty of contributing enhancements to an open platform. In consideration of these issues, the authors present an evaluation framework for ROER. Atenas and Havemann provide an extensive literature review of ROER, synthesise key themes from the literature and propose a range of quality indicators for repositories that inform development of their evaluation framework. They state their work is intended to aid current and future repository managers to assess the quality indicators that best fit the needs of the communities they aim to serve.

The final paper in this issue by Ahn, Pellicone and Butler (2014) continues with the question of openness through an exploration of open badges. The authors ask '... if anyone can create, issue and earn badges, what are the effects on the supply of such credentials, learner activity around these artefacts, and their interpretation of the meaning of badges?'. By restricting their analysis to a small number of characteristics, Ahn, Pellicone and Butler are able to provide us with an example of how we might evaluate the tensions and opportunities of badge systems as we experiment with open badges. Their discussion does not shrink from the complexities and conflicts in the intersection of openness and badges - rather we are encouraged to consider the issues and to participate in the collective research and improvement for functioning and high-impact badge systems. I, for one, am interested in watching this space. 


\section{References}

Ahn, J., Pellicone, A. \& Butler, B. S. (2014) 'Open badges for education: what are the implications at the intersection of open systems and badging?' Research in Learning Technology, 22: 23563, doi: http://dx.doi.org/10.3402/rlt.v22.23563

Atenas, J. \& Havemann, L. (2014) 'Questions of quality in repositories of open educational resources: a literature review', Research in Learning Technology, 22: 20889, doi: http://dx. doi.org/10.3402/rlt.v22.20889

Bennett, L. (2014) 'Learning from the early adopters: developing the Digital Practitioner', Research in Learning Technology, 22: 21453, doi: http://dx.doi.org/10.3402/rlt.v22.21453

Bennett, L. \& Folley, S. (2014) 'A tale of two doctoral students: social media tools and hybridised identities', Research in Learning Technology, 22: 23791, doi: http://dx.doi.org/10. 3402/rlt.v22.23791

Di Blas, N., Fiore, A., Mainetti, L., Vergallo, R. \& Paolini, P. (2014) 'A portal of educational resources: providing evidence for matching pedagogy with technology', Research in Learning Technology, 22: 22906, doi: http://dx.doi.org/10.3402/rlt.v22.22906

Mishra, P. \& Koehler, M. (2006) 'Technological pedagogical content knowledge: a framework for teacher knowledge', Teachers College Record, vol. 108, no. 6, pp. 1017-1054.

Orlando, J. (2014) 'Teachers' changing practices with information and communication technologies: an up-close, longitudinal analysis', Research in Learning Technology, 22: 21354, doi: http://dx.doi.org/10.3402/rlt.v22.21354

Scott, K.M. (2014) 'Taking over someone else's e-learning design: challenges trigger change in e-learning beliefs and practices', Research in Learning Technology, 22: 23362, doi: http://dx. doi.org/10.3402/rlt.v22.23362

Sharpe, R. \& Beetham, H. (2010) 'Understanding students' uses of technology for learning: towards creative appropriation', in Rethinking Learning for the Digital Age: How Learners Shape Their Experiences, eds. R. Sharpe, H. Beetham \& S. de Freitas, Routledge Falmer, London, pp. 85-99.

Dr. Meg O'Reilly

Center for Teaching and Learning

Southern Cross University

Lismore, NSW

Australia 